\title{
Comparative analysis of common genes involved in early fruit development in tomato and grape
}

\author{
Kentaro Mori ${ }^{1, *}$, Martine Lemaire-Chamley², Erika Asamizu', \\ Tsuyoshi Mizoguchi ${ }^{1}$, Hiroshi Ezura', Christophe Rothan ${ }^{2}$ \\ ${ }^{1}$ Gene Research Center, Graduate School of Life and Environmental Sciences, University of Tsukuba, Tsukuba, Ibaraki \\ 305-8572, Japan; ${ }^{2}$ UMR1332 Fruit Biology and Pathology, INRA-University of Bordeaux, 33140 Villenave d'Ornon, France \\ *E-mail: kentaro.mori@gene.tsukuba.ac.jp Tel: +81-29-853-7734
}

Received February 5, 2013; accepted March 21, 2013 (Edited by K. Aoki)

\begin{abstract}
Fleshy fruits are important worldwide crops that are rich sources of useful and functional compounds in the human diet. Although fruit ripening has been extensively studied, early fruit development has not been paid much attention despite its contribution to the sensorial and nutritional quality of the fruit. This study aimed at identifying candidate genes involved in early fleshy fruit development that can contribute to the control of final fruit size and composition by comparative analysis of tomato and grape genes. By mining public sequences and microarray database, we identified 23 transcription factors belonging to 14 classes (AP2-EREBP, ARF, bHLH, bZIP, C2C2-GATA, FHA, GeBP, GRAS, HB, LIM, MYB, PBF-2-like, SBP and WRKY) as candidate regulatory genes for early fruit development. The function of these candidate genes will be confirmed by several reverse genetic approaches using the miniature tomato cv. Micro-Tom.
\end{abstract}

Key words: Tomato, grape, early fruit development, transcription factor.

Fleshy fruits are important worldwide crops that are rich sources of useful and functional compounds in the human diet. These compounds (e.g. sugars, flavonoids, and volatile compounds) are mainly produced and/or accumulated at the ripening stage of fruit development (Giovannoni 2004). Extensive studies on fruit ripening have been done especially using tomato (Solanum lycopersicum) and have identified several key regulatory genes for the fruit ripening processes (Bemer et al. 2012; Karlova et al. 2011; Manning et al. 2006; Vrebalov et al. 2002 , 2009). In contrast, early stages of fruit development have not been paid much attention despite their large contribution to the visual, sensorial and nutritional quality of the fruit. After fruit set, successive cell division and cell expansion events mostly determine final fruit size (Gillaspy et al. 1993). At the same time, sugars, amino acid and organic acids accumulate during the cell expansion phase (Baxter et al. 2005; Carrari et al. 2006; Mounet et al. 2009). Although a few regulatory genes for fruit size and shape have been characterized (Cong et al. 2002; Frary et al. 2000; Xiao et al. 2008), molecular mechanisms underlying the regulation of fruit growth and metabolism during early fruit development are not fully addressed.

To identify candidate genes regulating early fruit development, we focused on grape (Vitis vinifera) which bears berry type fleshy fruits like tomato. In both tomato and grape, young fruits which have a green color present a rapid size increase by cell division and expansion. The transition phase to ripening is called "veraison" in grape, and breaker stage in tomato. After that, ripening stage consists in color changes, sugars accumulation and fruit softening, in both tomato and grape in spite of a main difference considering that tomato is climacteric and grape is non-climacteric. While grape has some unique characteristics such as the accumulation of tartaric acid instead of ascorbate (DeBolt et al. 2006) and the absence of endoreduplication-associated cell growth (Chevalier et al. 2011), tomato and grape have similar fruit developmental processes. In addition, comparative analysis of full-length cDNA sequences of Micro-Tom tomato cultivar with other plants indicated that tomato had higher similarity to grape than to other fleshy fruits like apple and orange (Aoki et al. 2010). Accordingly, a digital expression profiling revealed that some regulatory genes are up-regulated both in tomato and grape during fruit ripening (Fei et al. 2004).

In this study, we searched for candidate genes involved in early stages of fruit development that can contribute to final size and taste of fleshy fruit. After identification of tomato and grape common genes, transcriptome data mining highlighted several transcription factors having known and unknown biological role were found as the candidate genes. 


\section{Materials and methods}

\section{Identification of common genes between tomato and grape}

To identify common genes between tomato and grape, unigene data sets of the Tomato SGN Unigene (SGN build Tomato200607 \#1) and the NCBI Vitis vinifera UniGene (Build \#9) were retrieved from SGN and NCBI ftp site, respectively. Using the TBLASTX program (Altschul et al. 1990) with a cutoff $e$-value at 1e-10, the unigene sequences of tomato were compared with those of grape and vice versa. Reciprocal best hit pairs were determined as common gene pairs.

\section{Transcriptome data mining}

Publicly available microarray data of fruit development series in tomato and grape were obtained from TFGD (http://ted. bti.cornell.edu/cgi-bin/TFGD/miame/experiment.cgi?ID = E025; data set E025; Osorio et al. 2011) and PLEXdb (http:// www.plexdb.org/modules/PD_browse/experiment_browser. php?plex_name=GrapePLEX; data set VV5; Deluc et al. 2007), respectively. For TOM1 cDNA spotted array data set, the printtip LOWESS normalized data were used for further expression analysis. For grape microarray data set VV5, only the data of Cabernet Sauvignon berries from well-watered plants were used. The Affymetrix raw CEL files were processed for background correction, quantile normalization and a median polish with the robust multiarray averaging (RMA) method using RMAexpress program (Bolstad et al. 2003). Differentially expressed genes during fruit development were determined by one-way ANOVA with a false discovery rate (FDR) correction $(p<0.05$; Benjamini and Hochberg, 1995). Pearson's correlation $k$-means clustering of the differentially expressed probes corresponding to the common genes were performed using TM4: MeV 4.3 software (http://www.tm4.org; Saeed et al. 2003).

\section{Result and discussion}

\section{Comparison of unigene sequences between tomato and grape}

To identify common genes between tomato and grape, we compared 34,829 unigene data sets of tomato to 23,166 of grape. The TBLASTX reciprocal best hit method determined 8,229 unigenes as common gene pairs. This number should however be treated with caution and also take into account the redundancy derived from a same gene and the underestimate for paralogous gene families. Nevertheless, functional classification of common genes into Mapman BIN structure of tomato (Urbanczyk-Wochniak et al. 2006) showed higher proportion of common genes in the vital functions like those coding for co-factor and vitamin metabolism, C1-metabolism, mitochondrial electron transport/ ATP synthesis, biodegradation of xenobiotics and tetrapyrrole biosynthesis (Supplemental Figure 1). In contrast lower proportion of common genes was found in stress, glycolysis, photosynthesis, cell wall and not assigned categories.

\section{Comparative transcription analysis of common genes}

To identify common genes expressed in early stage of fruit development in tomato and grape, data-mining of publicly available microarray data of tomato and grape was performed. Among the 8,229 unigenes common to both tomato and grape, 2,503 unigenes (represented by 2,757 spotted probes) were present on tomato TOM1 array and 4,977 unigenes (represented by 6,203 spotted probes) were present on grape Genechip array. ANOVA analysis with a FDR cutoff of 5\% identified 1,713 probes in TOM1 and 3,922 probes in grape Genechip corresponding to genes differentially expressed throughout fruit development in tomato and grape, respectively. Among these, 885 probes representing genes included in both the tomato TOM1 and the grape Genechip were used for subsequent analysis.

Figure 1 shows transcription profiles along fruit development in tomato and grape resulting from $k$ means clustering for the 885 probes selected. The dotlines on each panel represent the transition phase to ripening, breaker at $42 \mathrm{DPA}$ in tomato and veraison ( 8 to 9 weeks after flowering) in grape. Based on this transition phase, 188 probes $(21 \%$ of the total number of probes analysed) represent genes induced during early development in both tomato and grape (clusters C, L, P and S). Conversely, 146 probes represent genes induced during ripening in both fruits (clusters D, E and F). The other probes did not show the same transcription profile in tomato and grape. Indeed the probes grouped in clusters $\mathrm{H}, \mathrm{M}$ and $\mathrm{R}$ represent genes induced during ripening in tomato but repressed during ripening in grape.

Mapman classification of the 182 genes (188 probes) expressed in early stages included e.g. 15 genes in the Photosynthesis category, 7 genes in Cell wall, 6 genes in Amino acid metabolism, 6 genes in Hormone metabolism, 5 genes in Stress, 20 genes in Protein synthesis, 8 genes in Protein degradation (see Supplemental Table S1 for exhaustive list). Comparison of apple and tomato gene expression data by Janssen et al. (2008) highlighted 41 genes expressed during early fruit development in both species. Only five of these genes were also found in the present study. They included 4 genes related to photosynthesis (SGN-U313179, SGN-U317999, SGN-U313194 and SGN-U312690) and one gene related to protein degradation (SGN-U313166). This may reflect actual variations in the control of early fruit development in the various fleshy fruit species, e.g. variations linked to fruit ontogeny (tomato and grape are berries while the fleshy tissues from apple arise from flower receptacle). However, possible 

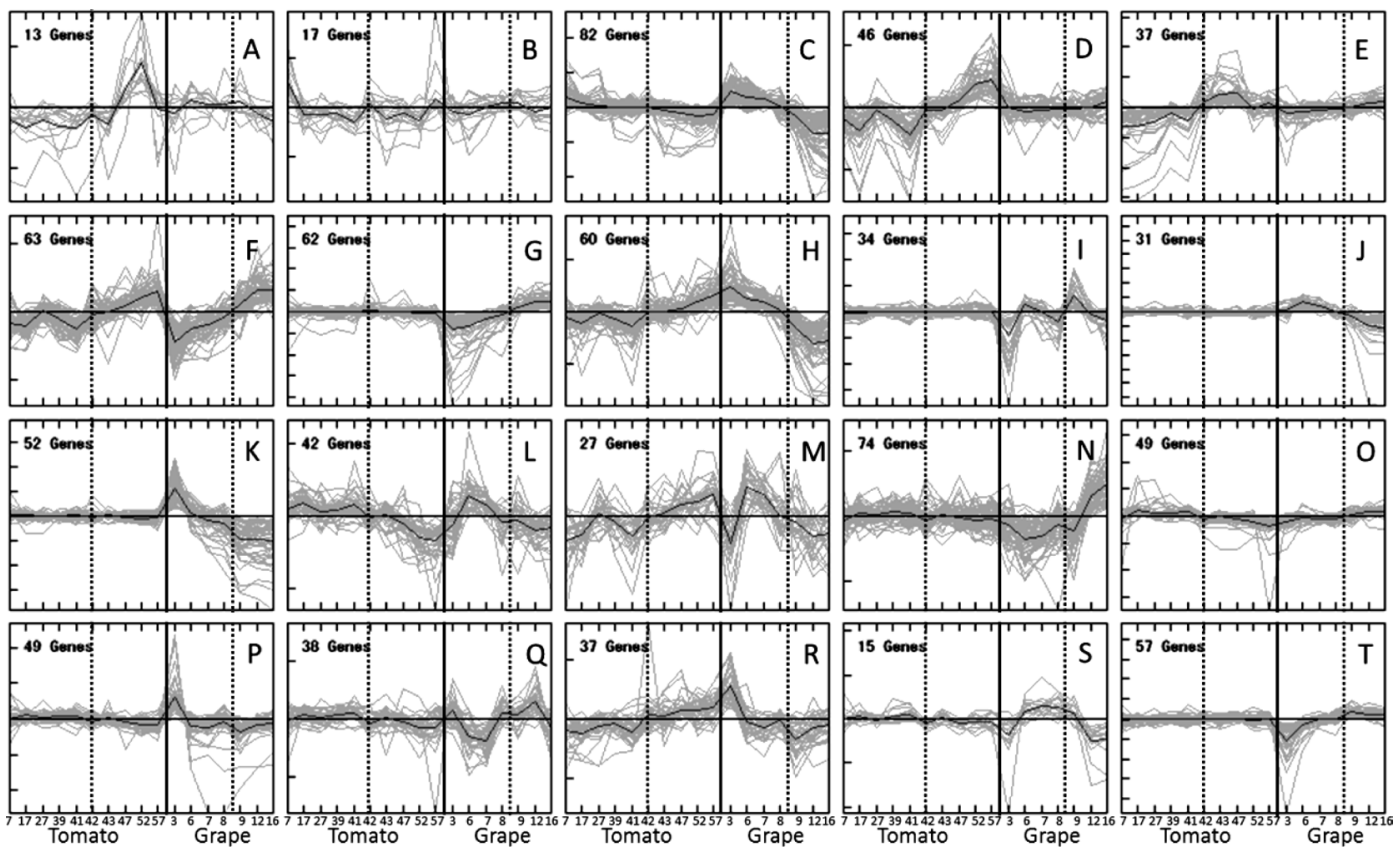

Figure 1. $k$-means clustering of tomato and grape common genes during fruit development. The dot-lines on each panel represent the breaker and veraison in tomato and grape, respectively. The scales on $x$-axis indicate the days post anthesis (DPA) and the weeks after flowering (WAF) in tomato and grape, respectively. The number indicated on the upper left corner indicates the number of probes in each cluster.

biases cannot be excluded, though the tomato TOM1 microarrays, cultivar and fruit stage of development were identical in the tomato/apple and tomato/grape experiments. Nevertheless, the 182 genes identified by current comparative transcript analysis of tomato and grape represent the major biological processes previously identified in early developing fruit (Gillaspy et al. 1993; Lemaire-Chamley et al. 2005; Mounet et al. 2009). Although several transcription factors (TFs) such as a Myb (SGN-U317694) and a bHLH (SGN-U320741) were included in the 182 early-expressed genes (Supplemental Table 1), no likely candidate regulatory gene controlling these biological processes was identified. The main reason was the lack of enough expression data, which resulted from the low number of probe sets corresponding to common genes that were spotted on the tomato TOM1 array (2,757 probes) compared to the grape Genechip array (6,203 probes).

\section{Candidate transcription factors involved in early fruit development}

To obtain further information on TFs expression during fruit development, we analyzed the data from Rohrmann et al. (2011) who accurately quantified the expression of approximately 1,000 tomato TFs using a high throughput quantitative real-time PCR platform and of Sweetman et al. (2012) who reported on the global transcriptome profiling of grape berry development by RNA-seq analysis. By mining the gene expression profiles obtained from the microarray analyses and from these references, we found 23 TFs which belong to 14 TF classes (AP2-
EREBP, ARF, bHLH, bZIP, C2C2-GATA, FHA, GeBP, GRAS, HB, LIM, MYB, PBF-2-like, SBP and WRKY; Perez-Rodriguez et al. 2010), which were expressed during early stages of fruit development in both tomato and grape (Table 1). Some of them have already been functionally characterized in tomato or in Arabidopsis, thus validating this tomato/grape comparative datamining approach for the identification of candidate gene for early fruit development. As an example, the auxin response factor SlARF4 (SGN-U319581) has been shown to be involved in the control of chlorophyll accumulation in the young fruit, in pericarp cell division, in fruit firmness and cell wall composition (Guillon et al. 2008; Jones et al. 2002). Recently, the involvement of SlARF4 in the control of sugar metabolism has also been reported (Sagar et al. 2013). Thus it is clear that SlARF4 is one of the important regulatory genes involved in early fruit development in tomato.

Among the 23 candidate TFs identified here (Table 1), five belong to the bHLH TFs class (SGN-U319163, SGN-U319813, SGN-U319853, SGN-U327501 and SGN-U320741) were found. The homologous genes of SGN-U319163 and SGN-U320741 in Arabidopsis are involved in brassinosteroid and auxin signaling (Rampey et al. 2006; Yin et al. 2005). Although the detailed role of brassinosteroid in fruit development is still unclear, BIM1 homolog (SGN-U319163) might be involved in early fruit growth. Indeed, brassinosteroids are produced during early stages of fruit development in both tomato and grape (Montoya et al. 2005; Symons et al. 2006). In addition, recent studies have demonstrated that bHLH 


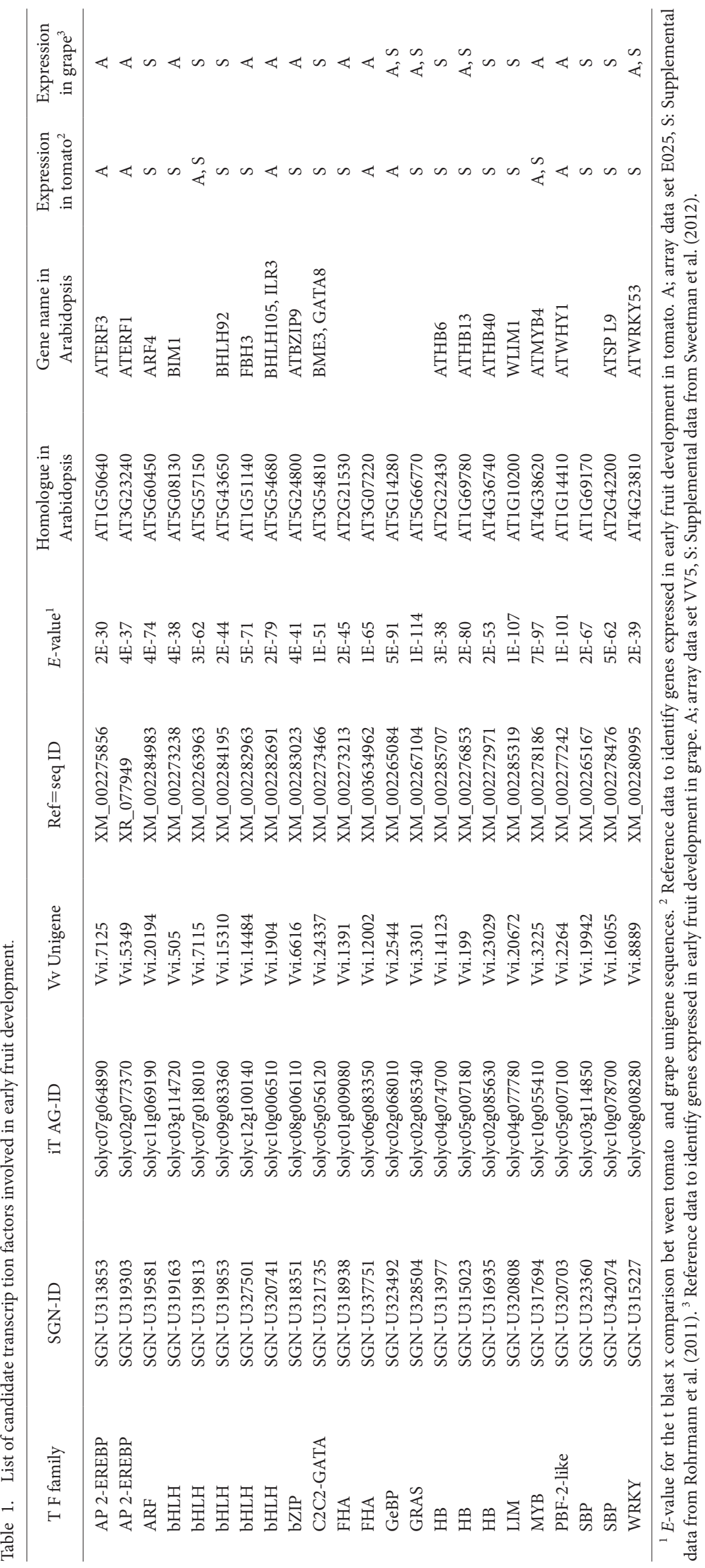


TFs play important roles in the control of cell elongation in Arabidopsis (Bai et al. 2012; Ikeda et al. 2012; Zhang et al. 2009). Furthermore, cross-species TF network analysis revealed that the other bHLH TF SGN-U319813 (Solyc07g018010) which was highly expressed in fruit tissue was correlated with photosynthetic tissue specific TFs (Rohrmann et al. 2012), suggesting that SGN-U319813 would be involved in the regulation of photosynthesis in the fruit. Taken together, these results suggest that the 5 bHLH TFs identified here are likely important candidate genes for the regulation of biological processes taking place in early developing fruit.

This study attempted to identify genes involved in the regulation of early fruit development by focusing on genes displaying similar patterns of expression in tomato and grape. Despite the lack of exhaustive gene expression data on early fruit development available in tomato and grape at the time of that study, we found using this approach one already known ARF gene with important biological role in fruit development and several other candidate genes. The role of these candidate genes in early fruit development will be confirmed by reverse genetic approaches including stable transformation, Tilling or VIGS in the miniature tomato cv. Micro-Tom.

\section{Acknowledgements}

This study was supported by the Japan-France Joint Laboratory Project, Ministry of Education, Culture, Sports, Science and Technology (MEXT), Japan and the JSPS-INRA Bilateral Joint Research Project.

\section{References}

Altschul S, Gish W, Miller W, Myers EW, Lipman DJ (1990) Basic local alignment search tool. J Mol Biol 215: 403-410

Aoki K, Yano K, Suzuki A, Kawamura S, Sakurai N, Suda K, Kurabayashi A, Suzuki T, Tsugane T, Watanabe M, et al. (2010) Large-scale analysis of full-length cDNAs from the tomato (Solanum lycopersicum) cultivar Micro-Tom, a reference system for the Solanaceae genomics. BMC Genomics 11: 210

Bai MY, Fan M, Oh E, Wang ZY (2012) A triple helix-loophelix/basic helix-loop-helix cascade controls cell elongation downstream of multiple hormonal and environmental signaling pathways in Arabidopsis. Plant Cell 24: 4917-4929

Baxter CJ, Carrari F, Bauke A, Overy S, Hill SA, Quick PW, Fernie AR, Sweetlove LJ (2005) Fruit carbohydrate metabolism in an introgression line of tomato with increased fruit soluble solids. Plant Cell Physiol 46: 425-437

Bemer M, Karlova R, Ballester AR, Tikunov YM, Bovy AG, Wolters-Arts M, Rossetto PDB, Angenent GC, de Maagd RA (2012) The tomato FRUITFULL homologs TDR4/FUL1 and MBP7/FUL2 regulate ethylene-independent aspects of fruit ripening. Plant Cell 24: 4437-4451

Benjamani Y, Hochberg Y (1995) Controlling the false discovery rate. JR Stat Soc 57: 289-300

Bolstad BM, Irizarry RA, Astrand M, Speed TP (2003) A comparison of normalization methods for high density oligonucleotide array data based on variance and bias.
Bioinformatics 19: 185-193

Carrari F, Fernie AR (2006) Metabolic regulation underlying tomato fruit development. J Exp Bot 57: 1883-1897

Chevalier C, Nafati M, Mathieu-Rivet E, Bourdon M, Frangne N, Cheniclet C, Renaudin J-P, Gévaudant F, Hernould M (2011) Elucidating the functional role of endoreduplication in tomato fruit development. Ann Bot (Lond) 107: 1159-1169

Cong B, Liu J, Tanksley SD (2002) Natural alleles at a tomato fruit size quantitative trait locus differ by heterochronic regulatory mutations. Proc Natl Acad Sci USA 99: 13606-13611

DeBolt S, Cook D, Ford C (2006) L-Tartaric acid synthesis from vitamin C in higher plants. Proc Natl Acad Sci USA 103: $5608-5613$

Deluc LG, Grimplet J, Wheatley MD, Tillett RL, Quilici DR, Osborne C, Schooley DA, Schlauch KA, Cushman JC, Cramer GR (2007) Transcriptomic and metabolite analyses of Cabernet Sauvignon grape berry development. BMC Genomics 8: 429

Fei Z, Tang X, Alba RM, White JA, Ronning CM, Martin GB, Tanksley SD, Giovannoni JJ (2004) Comprehensive EST analysis of tomato and comparative genomics of fruit ripening. Plant $J 40$ : 47-59

Frary A, Nesbitt TC, Frary A, Grandillo S, van der Knaap E, Cong B, Liu J, Meller J, Elber R, Alpert KB, et al. (2000) fw2.2: a quantitative trait locus key to the evolution of tomato fruit size. Science 289: 85-88

Gillaspy G, Ben-David H, Gruissem W (1993) Fruits: a developmental perspective. Plant Cell 5: 1439-1451

Giovannoni JJ (2004) Genetic regulation of fruit development and ripening. Plant Cell 16(Suppl): S170-S181

Guillon F, Philippe S, Bouchet B, Devaux M-F, Frasse P, Jones B, Bouzayen M, Lahaye M (2008) Down-regulation of an Auxin Response Factor in the tomato induces modification of fine pectin structure and tissue architecture. J Exp Bot 59: 273-288

Ikeda M, Fujiwara S, Mitsuda N, Ohme-Takagi M (2012) A triantagonistic basic helix-loop-helix system regulates cell elongation in Arabidopsis. Plant Cell 24: 4483-4497

Janssen BJ, Thodey K, Schaffer RJ, Alba R, Balakrishnan L, Bishop R, Bowen JH, Crowhurst RN, Gleave AP, Ledger S, et al. (2008) Global gene expression analysis of apple fruit development from the floral bud to ripe fruit. BMC Plant Biol 8: 16

Jones B, Frasse P, Olmos E, Zegzouti H, Li ZG, Latché A, Pech JC, Bouzayen M (2002) Down-regulation of DR12, an auxinresponse-factor homolog, in the tomato results in a pleiotropic phenotype including dark green and blotchy ripening fruit. Plant J32: 603-613

Karlova R, Rosin FM, Busscher-Lange J, Parapunova V, Do PT, Fernie AR, Fraser PD, Baxter C, Angenent GC, de Maagd RA (2011) Transcriptome and metabolite profiling show that APETALA2a is a major regulator of tomato fruit ripening. Plant Cell 23: 923-941

Lemaire-chamley M, Petit J, Garcia V, Just D, Baldet P, Fagard M, Mouassite M, Cheniclet C, Rothan C (2005) Changes in transcriptional profiles are associated with early fruit tissue specialization in tomato. Plant Physiol 139: 750-769

Manning K, Tör M, Poole M, Hong Y, Thompson AJ, King GJ, Giovannoni JJ, Seymour GB (2006) A naturally occurring epigenetic mutation in a gene encoding an SBP-box transcription factor inhibits tomato fruit ripening. Nat Genet 38: 948-952

Montoya T, Nomura T, Yokota T, Farrar K, Harrison K, Jones JDG, Jones JGD, Kaneta T, Kamiya Y, Szekeres M, et al. (2005) Patterns of Dwarf expression and brassinosteroid accumulation in tomato reveal the importance of brassinosteroid synthesis during fruit 
development. Plant J 42: 262-269

Mounet F, Moing A, Garcia V, Petit J, Maucourt M, Deborde C, Bernillon S, Le Gall G, Colquhoun I, Defernez M, et al. (2009) Gene and metabolite regulatory network analysis of early developing fruit tissues highlights new candidate genes for the control of tomato fruit composition and development. Plant Physiol 149: 1505-1528

Osorio S, Alba R, Damasceno CMB, López-Casado G, Lohse M, Zanor MI, Tohge T, Usadel B, Rose JKC, Fei Z, et al. (2011) Systems biology of tomato fruit development: combined transcript, protein and metabolite analysis of tomato transcription factor (nor, rin) and ethylene receptor $(\mathrm{Nr})$ mutants reveals novel regulatory interactions. Plant Physiol 157: 405-425

Perez-Rodriguez P, Riano-Pachon DM, Correa LGG, Rensing SA, Kersten B, Mueller-Roeber B (2010) PInTFDB: updated content and new features of the plant transcription factor database. Nucleic Acids Res 38 (Database issue): D822-D827

Rampey RA, Woodward AW, Hobbs BN, Tierney MP, Lahner B, Salt DE, Bartel B (2006) An Arabidopsis basic helix-loop-helix leucine zipper protein modulates metal homeostasis and auxin conjugate responsiveness. Genetics 174: 1841-1857

Rohrmann J, McQuinn R, Giovannoni J, Fernie AR, Tohge T (2012) Tissue specificity and differential expression of transcription factors in tomato provide hints of unique regulatory networks during fruit ripening. Plant Sig Beh 7: 1639-1647

Rohrmann J, Tohge T, Alba R, Osorio S, Caldana C, McQuinn R, Arvidsson S, van der Merwe MJ, Riaño-Pachón DM, MuellerRoeber B, et al. (2011) Combined transcription factor profiling, microarray analysis and metabolite profiling reveals the transcriptional control of metabolic shifts occurring during tomato fruit development. Plant J 68: 999-1013

Saeed AI, Sharov V, White J, Li J, Liang W, Bhagabati N, Braisted J, Klapa M, Currier T, Thiagarajan M, et al. (2003) TM4: a free, open-source system for microarray data management and analysis. Biotechniques 34: 374-378

Sagar M, Chervin C, Mila I, Hao Y, Roustan J-P, Benichou M,
Gibon Y, Biais B, Maury P, Latche A, et al. (2013) Sl-ARF4, an Auxin Response Factor involved in the control of sugar metabolism during tomato fruit development. Plant Physiol 161: $1362-1374$

Sweetman C, Wong DC, Ford CM, Drew DP (2012) Transcriptome analysis at four developmental stages of grape berry (Vitis vinifera cv. Shiraz) provides insights into regulated and coordinated gene expression. BMC Genomics 13: 691

Symons GM, Davies C, Shavrukov Y, Dry IB, Reid JB, Thomas MR (2006) Grapes on steroids. Brassinosteroids are involved in grape berry ripening. Plant Physiol 140: 150-158

Urbanczyk-Wochniak E, Usadel B, Thimm O, Nunes-Nesi A, Carrari F, Davy M, Bläsing O, Kowalczyk M, Weicht D, Polinceusz A, et al. (2006) Conversion of MapMan to allow the analysis of transcript data from Solanaceous species: effects of genetic and environmental alterations in energy metabolism in the leaf. Plant Mol Biol 60: 773-792

Vrebalov J, Pan IL, Arroyo AJM, McQuinn R, Chung M, Poole M, Rose J, Seymour G, Grandillo S, Giovannoni J, et al. (2009) Fleshy fruit expansion and ripening are regulated by the Tomato SHATTERPROOF gene TAGL1. Plant Cell 21: 3041-3062

Vrebalov J, Ruezinsky D, Padmanabhan V, White R, Medrano D, Drake R, Schuch W, Giovannoni J (2002) A MADS-box gene necessary for fruit ripening at the tomato ripening-inhibitor (rin) locus. Science 296: 343-346

Xiao H, Jiang N, Schaffner E, Stockinger EJ, van der Knaap E (2008) A retrotransposon-mediated gene duplication underlies morphological variation of tomato fruit. Science 319: 1527-1530

Yin Y, Vafeados D, Tao Y, Yoshida S, Asami T, Chory J (2005) A new class of transcription factors mediates brassinosteroidregulated gene expression in Arabidopsis. Cell 120: 249-259

Zhang L-Y, Bai M-Y, Wu J, Zhu J-Y, Wang H, Zhang Z, Wang W, Sun Y, Zhao J, Sun X, et al. (2009) Antagonistic HLH/bHLH transcription factors mediate brassinosteroid regulation of cell elongation and plant development in rice and Arabidopsis. Plant Cell 21: 3767-3780 